\title{
BASES TEÓRICAS PARA A CONCEITUAÇÃO E CONSTRUÇÃO DE TECNOLOGIAS CÍVICAS
}

\author{
THEORETICAL BASES FOR THE CONCEPTUALIZATION AND CONSTRUCTION OF \\ CIVIC TECHNOLOGIES
}

\section{BASES TEÓRICAS PARA LA CONCEPTUALIZACIÓN Y CONSTRUCCIÓN DE TECNOLOGÍAS CÍVICAS}

\author{
Alvaro Martins Fernandes Júnior \\ Doutor em Educação: Currículo pela PUC-SP. Professor na Escola Superior de Gestão Pública, Política, \\ Jurídica e Segurança do Centro Universitário Internacional UNINTER, Curitiba/PR-Brasil. \\ ORCID: https://orcid.org/0000-0003-0726-1177, e-mail: alvarojunior777@gmail.com \\ Jorge Luiz Bernardi \\ Doutor em Gestão Urbana pela Pontifícia Universidade Católica do Paraná - PUCPR \\ Vice-Reitor do Centro Universitário Internacional UNINTER, Curitiba/PR-Brasil. \\ ORCID: https://orcid.org/0000-0002-2449-7360, e-mail: jorge.b@uninter.com
}

\begin{abstract}
RESUMO
O presente texto é um ensaio teórico sobre tecnologias cívicas. Devido à escassa literatura nacional disponível sobre o tema, justifica-se a necessidade de apontar bases conceituais para o desenvolvimento de pesquisas na área, bem como a disseminação do uso e produção de tais tecnologias. Para essa construção teórica, dialoga-se com autores como Douglas Rushkoff (2010, 2019), Pierre Levy (2000, 2004), Duncan Green (2009), De Masi (2014), Bauman e Bordoni (2016), entre outros. O estudo indica que as tecnologias cívicas são vias de comunicação criadas por intermédio das tecnologias digitais, com vistas à promoção de ações que reduzam ciclos de reprodução de pobreza e desigualdade e fortaleçam o espírito democrático.
\end{abstract}

Palavras-chave: Tecnologias cívicas; Vias de comunicação; Democracia.

\section{ABSTRACT}

This text is a theoretical essay on civic technologies. Due to the scarce national literature available on the subject, the need to point out conceptual bases to develop research in the area is justified, as well as in the dissemination of the use and production of civic technologies. For this theoretical construction, we dialogue with authors such as Douglas Rushkoff (2010, 2019), Pierre Levy (2000, 2004), Duncan Green (2009), De Masi (2014), Bauman and Bordoni (2016), among others. The study indicates that civic technologies are means of communication, created through digital technologies, with a view to promote actions that reduce cycles of poverty and inequality reproduction and strengthen the democratic spirit.

Keywords: Civic technologies; Communication ways; Democracy.

\section{RESUMEN}

Este texto es un ensayo teórico sobre tecnologías cívicas. Dada la escasa literatura nacional disponible sobre el tema, se justifica la necesidad de señalar bases conceptuales para el desarrollo de investigaciones en el área, así como la difusión del uso y producción de tales tecnologías. Para esa construcción teórica, se dialoga con autores como Douglas Rushkoff (2010, 2019), Pierre Levy (2000, 2004), Duncan Green (2009), De Masi 
(2014), Bauman y Bordoni (2016), entre otros. El estudio señala que las tecnologías cívicas consisten en vías de comunicación creadas a través de tecnologías digitales, con el fin de promover acciones que reduzcan los ciclos de reproducción de pobreza y desigualdad y fortalezcan el espíritu democrático.

Palabras-clave: Tecnologías cívicas; Vías de comunicación; Democracia.

\section{INTRODUÇÃO}

Em 1944, o antropólogo Alfred Kroeber publicou seu livro Configurations of Culture Growth, que tinha como objetivo mapear os altos e baixos das realizações humanas. $O$ antropólogo acreditava ser a cultura, e não a genética, que explicava a profusão de gênios, como na Atenas de Sócrates, Platão, Aristóteles, Epicuro, Parmênides, entre outros. O autor tentou explicar, também, porque essas eras de ouro chegavam ao fim. Conforme Kroeber, cada cultura é como um chefe de cozinha, e quanto mais ingredientes (configurações culturais, nas palavras do autor), maior será a possibilidade de pratos a serem criados. Entretanto, mesmo as cozinhas mais abastecidas se esgotam; com a morte de Sócrates, em 399 a.C., a dispensa ficou vazia, restando assim, apenas a possibilidade de plagiarem a si mesmo (WEINER, 2016).

Esses não foram os únicos deslizes dos atenienses; a democracia era restrita a apenas uma parte da população, a xenofobia e a expedição à Sicília, por exemplo, foram alguns erros que podemos citar (WEINER, 2016).

A podridão e os problemas vinham de dentro também. As casas ficaram maiores e mais ostentosas. As ruas ficaram mais largas e a cidade menos íntima. As pessoas desenvolveram gostos sofisticados. A diferença entre ricos e pobres, cidadãos e não cidadãos ficou maior, enquanto sofistas que vendiam suas acrobacias verbais ficaram mais influentes. O meio acadêmico passou a ter menos a ver com a busca da verdade e mais com a análise dessas verdades. A vida urbana, antes vibrante, degenerou-se em um ambiente de circo. "[...] Todo lugar de genialidade, na atualidade ou no passado, vai conter sementes de sua própria destruição." (WEINER, 2016, p. 74).

Corroborando Kroeber, podemos sugerir que as cidades educadoras devem ser ricas em proporcionar ingredientes, de modo que a cultura possa efervescer e, assim, criar mais pratos, "culturas que possuem povos que não têm acesso à educação, não produzirão grandes avanços tecnológicos." (THUROW, 2001 apud FERNANDES JUNIOR et al. 2019, p. 
140). Assim, é necessário preparar o terreno para continuar evoluindo (FERNANDES JÚNIOR; ALMEIDA; ESTEVEZ, 2015).

Se é por meio de oportunidades educacionais, sejam em contextos formais, não formais ou informais, que os avanços tecnológicos e a inovação acontecem, é fato afirmar que, se não se propiciam essas oportunidades a todas as pessoas, muito talento e genialidade é desperdiçada. Com um espírito cívico e tecnológico, é possível mudar tal panorama e permitir que toda a inventividade do talento humano aflore (FERNANDES JUNIOR et al., 2019).

O foco deste texto são as tecnologias cívicas como propulsora de um mundo mais virtuoso e ético (FERNANDES JUNIOR et al., 2019); assim, o foco é apresentar bases teóricas para a construção de um entendimento sobre tais tecnologias e como podem auxiliar na proposição de ingredientes para as cidades.

Afinal, a tecnologia, quando combinada com o espírito humano, tem a capacidade de revolucionar indústrias inteiras e o mundo - objetivo primordial das tecnologias cívicas. Elas visam um futuro melhor, em que o maior número de pessoas tem acesso às tecnologias, e por consequência, podem exercer seus diretos e deveres. Quando falamos em tecnologias cívicas, estamos mais preocupados com a postura perante os aparatos tecnológicos, do que com eles em si. Destarte, precisamos refletir sobre o uso das tecnologias; devemos utilizá-las para reduzir ciclos de reprodução de desigualdades e pobreza, e não para aumentá-los.

\section{Tecnologias cívicas na contemporaneidade}

Desde as últimas décadas do século passado, vivemos em uma sociedade cujo período histórico é cunhado por llya Prigogine como "o fim das certezas"; afirma que a dúvida é salutar para o desenvolvimento humano e que, aquilo que um dia foi caracterizado como absoluto, pode ser questionado, averiguado e até negado, caracterizando a sociedade por sua leveza, liquidez, capilaridade e, para usar uma expressão cunhada por Castells, "em forma de rede" (CASTELLS, 2010).

Vivemos tempos pós-modernos e, nestes tempos, vários conceitos que foram caros ao pensamento moderno - como razão, sujeito, totalidade, verdade e progresso - 
entram em crise; a partir disso, novos ordenamentos teóricos surgiram, como: aumento de potência, eficácia e otimização de performance de sistema (LYOTARD, 1986).

Lyotard (1986, p. 8) versa que "o cenário pós-moderno é essencialmente cibernético-informático e informacional”, e, no intuito de conhecer essa dinâmica, o foco passou a ser as pesquisas em linguagem, para que, em breve, o homem possa dominá-la ou até entender como elas aprendem (inteligência artificial e aprendizagem de máquinas). O cérebro humano e os mecanismos da vida continuam a ser estudados, de modo a ser imitado pela máquina. Nesta perspectiva, os esforços científicos, tecnológicos e políticos passaram a objetivar a informatização da sociedade.

Se a Revolução Industrial nos mostrou que sem riqueza não se tem tecnologia ou mesmo ciência, a condição pós-moderna nos mostra o oposto; sem saber científico e técnico, não há riqueza. Assim, a riqueza de um país não é mais medida pela quantidade de toneladas que estes podem produzir ou manufaturar, mas sim, pela quantidade de informação técnico-cientifica que suas universidades e centros de pesquisa podem gerar e fazer circular como mercadoria.

A pós-modernidade está relacionada à queda do que Lyotard (1986) chama de metanarrativas - grandes esquemas filosóficos e metafísicos universalizantes e atemporais. Se antes estava tudo posto e explicado, hoje em dia, o que fica, são as incertezas e o relativismo.

Bauman e Bordoni (2016) postulam que atualmente a ideia de crise tende a voltar a sua origem: na medicina. Quando ela foi cunhada, denotava o momento em que o médico tinha que decidir qual destino um paciente convalescente tomaria.

O termo crise, assim, está relacionado à tomada de decisão, e não necessariamente a momentos ruins, "quando diagnosticamos uma situação de 'crítica', é exatamente isso que queremos dizer, a conjunção de um diagnóstico e um chamado a ação" (BAUMAN; BORDONI, 2016, p. 16).

O Estado de crise é também a crise do Estado, são duas faces da mesma moeda. Se no passado o Estado tinha poder e política para emplacar as decisões necessárias para sair da crise, hoje ele perdeu essa capacidade. Seu poder de realizar ações foi capturado por forças supraestatais (globais) que operam em um "espaço de fluxos", em que o Estado não tem como interferir. 
O fato das crises se moverem mais lentamente que as demais atividades humanas tornam os prognósticos obsoletos rapidamente. Quando uma crise acaba, outra, que aparentemente não causaria impacto, toma conta. Isso nos coloca em um estado de crise permanente, tornando necessário que aprendamos a viver com isso, para estarmos atentos e preparados psicologicamente para o pior (BAUMAN; BORDONI, 2016).

Os autores ainda argumentam que, além do poder para fazer as coisas acontecerem, o Estado perdeu, também, a criatividade necessária para a tomada de decisões, pois a mão invisível do mercado não é mais capaz de nos retirar deste estado de crise. Então, em um momento de crise, o arsenal humano para tomar decisões está tomado por incertezas e projetos que ainda nem saíram do papel.

Todos estão perguntando como chegamos aqui, como se isso fosse um deslize aleatório em direção à incoerência e desempoderamento coletivos. Não é. Há uma razão para nossa situação atual: uma agenda antihumana embutida em nossa tecnologia, nossos mercados e nossas principais instituições culturais, desde educação e religião até educação cívica e mídia. Transformou-os de forças de conexão e expressão humanas em forças de isolamento e repressão. Ao desenterrar essa agenda, nos tornamos capazes de transcender seus efeitos paralisantes, reconectando-nos uns aos outros e reconstruindo a sociedade para fins humanos, em vez do fim dos humanos (RUSHKOFF, 2019, p. 5)

Na atual conjuntura, ao realizar um exame de consciência, verificamos que estar em crise não é a realidade, mas sim “[...] a nossa maneira de interpretá-la, os nossos modelos: uma vez que as categorias mentais oriundas da época industrial já não são capazes de explicar o presente, acabamos sendo induzidos a desconfiar do futuro." (DE MASI, 2014, p. 17).

O filósofo esloveno Slavoj Zizek argumenta que as coisas não vão bem no que ele chama de "paraíso capitalista global" e - embora estejamos em crise permanente aceitamos que o capitalismo é a melhor das opções que temos. Entretanto, o autor versa que, se almejamos realmente um futuro melhor, é o capitalismo que tem de ser combatido.

O esloveno concorda com autores como Yuval Harari e Steven Pinker que argumentam que, atualmente, vivemos melhor do que nossos ancestrais. "Sim, hoje em dia vivemos definitivamente melhor do que nossos ancestrais de 10 mil anos atrás na Idade da Pedra." (ZIZEK, 2015, p.25); contudo, o autor aponta que falta aos indivíduos saber ler as entrelinhas, do dito e não dito. 
Logo, é preciso que os indivíduos se unam para encontrarem soluções para sairmos de que nós mesmos (enquanto humanidade) nos colocamos (RUSHKOFF, 2019).

\section{Reflexões acerca das tecnologias cívicas}

Para falar de civismo, é necessário falar de cidadania, pois ambas são condições necessárias para a consolidação da democracia em uma sociedade; a primeira relaciona-se com a garantia dos direitos fundamentais dos cidadãos, como a liberdade e a igualdade, e a segunda convida à participação ativa dessas pessoas, exercendo seus direitos enquanto cidadãos.

A cidadania, então, consiste no conjunto de direitos e deveres ao qual o cidadão que vive em uma sociedade está sujeito. O civismo, em sua essência, consolida-se por meio das atitudes e comportamentos que os cidadãos manifestam no dia a dia, tudo no intuito da defesa de valores e práticas fundamentais à vida coletiva, de modo a preservar a harmonia e melhorar o bem-estar de todos. Ações cívicas centram-se nas práticas do nosso cotidiano e no modo como os cidadãos agem, contribuindo para melhorar o bem-estar em sociedade. Um cidadão que conhece suas obrigações pode e deve ser cobrado quando deixa de cumpri-las.

Estamos incorporando algumas noções muito antigas e depreciativas sobre os seres humanos e seu lugar na ordem natural em nossa futura infraestrutura tecnológica. Os engenheiros de nossas principais empresas de tecnologia e universidades tendem a ver os seres humanos como o problema e a tecnologia como a solução (RUSHKOFF, 2019, p. 7).

Outro conceito importante é o de democracia, cuja discussão sobre o tema se iniciou a 2500 anos, quando os gregos refletiam sobre qual seria a forma de governo ideal para a realização das potencialidades humanas. Em sua concepção original, o termo significava poder do povo (ABBAGNANO, 2007); no entanto, o conceito de democracia da sociedade atual difere, significativamente, daquele postulado pelos gregos e pelos filósofos Locke e Rousseau (MEDEIROS, 2016). O conceito atual é o que Giovanni Sartori (1994) chama de democracia confusa, ou seja, o uso do termo hoje ultrapassa sua concepção inicial de "forma de governo" para indicar "um modo de ser e pensar" (ABBAGNANO, 2007, p. 277). 
A própria democracia grega, citada frequentemente como a opção a ser seguida, não é o melhor dos exemplos, pois, nela, apenas homens, filhos de pai e mãe atenienses, livres e maiores de 21 anos tinham direito à participação política, enquanto estrangeiros, escravos e mulheres eram grupos excluídos dela; logo, o maior exemplo de democracia citado nos debates não é a democracia que queremos.

Na contemporaneidade, a democracia é considerada uma política humana, ou seja, a serviço do homem por uma convivência que permita a sua realização; nessa perspectiva, Abbagnano corrobora com Bobbio quando afirma que a democracia é "a política que tem em vista o homem, em oposição às políticas que o veem como instrumento, determinando seus objetivos." (ABBAGNANO, 2007, p. 277).

As conexões sociais são importantes para nos orientar, garantir sobrevivência e alcançar entendimento e propósito; isto é, consiste no legado biológico da humanidade. Pessoas que se desconectam, seja de suas organizações ou comunidades, muitas vezes murcham sem elas. No início dos tempos, a conexão para buscar por comidas ou fugir de presas era mais comum; atualmente, entretanto, esse relacionamento é para o próprio bem, "porque ganhamos força, prazer e propósito à medida que desenvolvemos relacionamento." (RUSHKOFF, 2019, p.5).

Rushkoff apresenta em seu livro Programe ou seja programado: Dez comandos para uma vida digital (2010) a tese de que ou aprendemos a criar softwares ou nós seremos o software; aprendemos a programação, ou seremos programados. "Escolha o primeiro e você terá acesso ao painel de controle da civilização. Escolha o último, e pode ser a última escolha real que você poderá fazer." (RUSHKOFF, 2010, p. 8).

O autor alega que algumas expectativas com relação à disponibilização e ao advento da internet não foram atendidas, "uma sociedade que encarava a Internet como um caminho em direção a conexões altamente articuladas e novos métodos de criação de significado está se desconectando, negando o pensamento profundo e drenando valores duradouros." (RUSHKOFF, 2010, p. 10).

Com base nas reflexões de Rushkoff (2010), apresentamos, no Quadro 1, as expectativas e a realidade do acesso à internet. 
Quadro 1 - Expectativas e realidade do acesso à internet

Expectativa

Os educadores desejavam discutir a informação disponível na web com os alunos.

Os pais acreditaram que seus filhos seriam multitarefas.

Os jovens que viam nas redes a possibilidade de se redefinirem.

Fonte: elaborado pelo autor, baseado em Rushkoff (2010).

\section{Realidade}

Os alunos se contentam com uma simples pesquisa na Wikipédia.

Os filhos estão perdendo a capacidade de concentração em qualquer coisa.

Os jovens se conformaram com a lógica dos perfis das redes sociais.

Rushkoff nos convida a realizar uma pausa e refletir sobre o futuro do nosso trabalho, de nossas vidas e de nossa espécie. O autor ainda contrapõe a ideia de inteligência coletiva de Pierre Levy, e afirma que o mundo cibernético é mais uma multidão cibernética do que um cérebro coletivo, pois “As pessoas estão sendo reduzidas a sistemas nervosos configuráveis externamente, enquanto os computadores são livres para interagir em rede e pensar de maneiras mais avançadas do que jamais imaginaremos." (RUSHKOFF, 2010, p. 11).

Cada revolução da mídia propiciou novas experiências nos modos com que nos relacionamos com o mundo. Com o advento de um novo meio, o status quo não é apenas examinado; é revisado e reescrito por aqueles que ganharam novo acesso às ferramentas de sua criação.

A invenção da prensa de Gutenberg no Renascimento, por exemplo, não ocasionou uma sociedade de escritores, mas sim de leitores. O cinema tem o seu embrião no desejo de Lumiére de conferir movimento às imagens estáticas, com vistas ao desenvolvimento de pesquisas científicas; entretanto, na visão do seu inventor, esse meio não teria futuro como espetáculo. Esse entendimento de que as invenções impactam além daquilo para o qual foram criadas é também uma das linhas centrais de Rushkoff.

\footnotetext{
Simplesmente usamos os programas que foram criados para nós e inserimos nosso texto na caixa apropriada na tela. Ensinamos as crianças a usar softwares para escrever, mas não como escrever softwares. Isso significa que eles têm acesso aos recursos que lhes são dados por outros, mas não têm o poder de determinar por si mesmos os recursos de criação de valor dessas tecnologias (RUSHKOFF, 2010, p. 13).
}

Enquanto uma elite domina e cria utilizando uma nova tecnologia, uma vastidão de pessoas apenas faz uso não reflexivo delas; por exemplo, nós assistimos TV, não criamos programas de TV. No fim, nos maravilhamos com a tecnologia e não com a técnica, com os computadores e não com o que as pessoas conseguem fazer de positivo com eles, "em vez 
de otimizar nossas máquinas para a humanidade, estamos otimizando humanos para máquinas." (RUSHKOFF, 2010, p. 15).

À medida que nossa própria obsolescência se aproxima, continuamos a aceitar novas tecnologias em nossas vidas, com pouco ou nenhum entendimento de como esses dispositivos funcionam e nos influenciam.

É somente entendendo os vieses da mídia, através da qual nos envolvemos com o mundo, que podemos diferenciar entre o que pretendemos e o que as máquinas que estamos usando pretendem para nós.

\section{Mitigando o acidente integral}

A Sociedade em Rede é o primeiro de três volumes da trilogia Era da Informação: Economia, sociedade e cultura, criada pelo sociólogo espanhol Manuel Castells. O título é originalmente de 1996 e visava compreender como a comunicação, mediada por computadores, mídias digitais e o ciberespaço, influenciava as relações de trabalho, no capitalismo, na cultura e nos relacionamentos.

Um novo sistema de comunicação, falando cada vez mais uma linguagem universal, digital, que está tanto integrando globalmente a produção e distribuição de palavras, sons e imagens de nossa cultura, quanto customizando-os para os gostos das identidades e humores dos indivíduos. As redes interativas de computadores estão crescendo exponencialmente, criando formas e canais de comunicação, moldando a vida e sendo moldados pela vida ao mesmo tempo. (CASTELLS, 2010, p. 2)

As redes estão em constante movimento, se abrindo e se fechando, aumentando e diminuindo, conforme novos "nós" vão se interconectando ou se desconectando. As redes não possuem fronteiras geográficas, se estabelecem e se esvaem no ciberespaço; assim, na sociedade em rede, o grande poder é o poder da comunicação (CASTELLS, 2010).

À todas essas características, Castells dá o nome de "capitalismo informacional", que remete ao poder dos dados e informações que se distribuem pelas redes e se tornam bens preciosos - à medida que decisões de alcance global são tomadas quando se tem acesso a eles, pois, "a produção, troca, organização e consumo de informações é uma das características principais do mundo contemporâneo." (MARTINO, 2014, p. 100). 
O que caracteriza a atual revolução tecnológica não é a centralidade do conhecimento e da informação, mas sim, a aplicação destes aos dispositivos de geração de conhecimento e processamento de informações/comunicação, em um loop cumulativo de feedback entre a inovação e os usos da inovação (CASTELLS, 2010); por isso, a informação é importante.

Esse novo paradigma de comunicação, apoiado pela Tecnologia da Informação e Comunicação (TIC), coloca os usuários finais no centro dos processos de inovação, mudando, assim, a ênfase da tecnologia para as pessoas.

Paul Virilio é um arquiteto, urbanista e filósofo francês. Sua área de estudos é conhecida por Dromologia (termo cunhado por ele), que significa a ciência/estudo da lógica da velocidade. Consiste em uma área de estudos interdisciplinares que visa explicar como a velocidade empreendida pelas novas tecnologias alteram a essência da natureza dos fenômenos políticos, sociais e culturais.

O autor versa que, pela primeira vez na humanidade, tempo humano e tempo tecnológico estão sincronizados, isto é, podemos estar aqui e lá ao mesmo tempo: instantaneidade, ubiquidade e imediaticidade; entretanto, tal aceleração nos tornou inertes, o que nos conduziu a um estado em que poderemos delegar mais poder às máquinas.

A tese do pensador é simples; toda técnica traz consigo o seu acidente, explico: antes do navio não havia acidente de navio, assim como antes do avião não havia acidente de avião e assim vai. É o que ele intitula de demonstração dos limites da técnica.

Durante sua vida, Virilio escreveu para alertar para o que ele chama de "Acidente Integral", o acidente de todos os acidentes. Esse será o momento em que delegaremos todo o poder às máquinas, quando o tempo tecnológico ultrapassará o humano.

Enquanto as outras técnicas tinham apenas seus acidentes em locais específicos, por exemplo, o Titanic afundou em um local do Oceano Atlântico, ou um avião em algum local do hemisfério norte, o acidente dos acidentes terá impactos globais pelo fato de estarmos todos controlados e conectados à mesma rede. A crise de 1929 nos Estados Unidos e a do Lemman Brothers em 2008 são apenas presságio; assim, as tecnologias cívicas podem nos auxiliar a mitigar esse acidente integral.

É fato que o grande desenvolvimento tecnológico da humanidade é catalisado pelas grandes guerras (SEVCENKO, 2001), mas isso não nos inibe de fazer o uso das tecnologias, 
com vistas à virtude e o bem comum. Assim, embora a internet não seja inerentemente cívica, ela catalisa e enriquece movimentos que promovem a democracia, o desenvolvimento dos povos e a cidadania - e isso é cívico. Quando uma tecnologia é atualizada e atende as suas pretensões iniciais, versões mais simples destas tecnologias são disponibilizadas para exploração comercial daqueles que podem pagar por seu alto preço. Destarte, a internet só vai cumprir o seu papel cívico integralmente quando todos tiverem acesso a ela, mas estamos longe disso.

Segundo o Data Reportal (2021), quase 3 bilhões de pessoas não possuem conexão à internet no globo; a maioria dessas pessoas está concentrada no sul (1,12 bilhões) e leste (493 milhões) da Ásia, e no leste do continente africano (340 milhões).

Os números altos concentrados no sul da Ásia são capitaneados pela Índia, país cuja população é de 1,39 bilhões de habitantes, e 55\% ainda não usa a internet, isto é, mais de 700 milhões de pessoas não navegam no ciberespaço (DATAREPORT, 2021). Em Bangladesh, país cuja população é de 165,5 milhões, 71,2\% dos habitantes ainda não tem acesso à internet, o que significa que 117,9 milhões de pessoas não navegam no ciberespaço (DATAREPORT, 2021).

De acordo com uma pesquisa publicada por Mckinsey\&Company, os países africanos gastam, em média, cerca de 1,1\% do PIB com investimento em "tornar-se digital" (incluindo infraestrutura e redes de internet), enquanto os países desenvolvidos gastam 3,2\% do PIB (GRIJPINK; MÉNARD; SIGURDSSON; VUCEVIC, 2018).

A ITU (International Telecommunication Union) afirmou em 2018 que a infraestrutura necessária para conectar mais 1,5 bilhões de pessoas deveria custar 450 bilhões de dólares.

\section{Conceitos e características das tecnologias cívicas}

Em uma busca realizada na plataforma Scielo, não foram encontradas pesquisas com a palavra-chave “tecnologias cívicas” marcando todos os índices; já no Google Scholar, encontram-se apenas 56 resultados, nem todos acessíveis para leitura. Um desses estudos é o trabalho de Nohara e Colombo (2019), que embora não discorram sobre o conceito, apontam a inteligência artificial como uma grande tecnologia cívica. O catálogo de teses e dissertações da Capes apresentou apenas dois resultados, sendo um sem divulgação autorizada. 
O termo tecnologia cívica carece de delimitação conceitual, mas isso não é ruim; a polissemia também indica riqueza e, principalmente, que os estudos ainda são incipientes. Uma explicação para essa ausência conceitual bem definida é com relação ao tamanho do seu mercado, que pode ser entendido como enorme quando analisamos o modo como as pessoas usam as tecnologias, e muito pequeno, quando pensamos em tecnologias criadas para serem cívicas.

Ainda nessa perspectiva de mercado, há os players lucrativos e outros sem fins lucrativos; no entanto, não há fronteiras perfeitas entre os serviços e produtos ofertados por essas organizações. Outro ponto, é sua terminologia, oriunda do inglês, Civic tech; quando se digita esse termo nos buscadores, depara-se com informações sobre o carro Honda Civic e sua tecnologia.

Skaržauskienè e Mačiulienè (2020) apontam que a tecnologia cívica é um termo abrangente para definir iniciativas digitais da sociedade civil, organizações privadas e cidadãos individuais.

A tecnologia cívica está relacionada, em grande parte, com a Tecnologia da Informação, que permite a criação de aplicativos cívicos, plataformas de apoio a órgãos governamentais, instituições, e outros softwares que possibilitam a aproximação do governo com as necessidades populacionais; cria-se, assim, canais de comunicação entre a população e os governantes. Tais canais permitem que esses cidadãos influenciem as decisões dos órgãos públicos - o que possibilita uma melhor prestação de serviços pelo governo. O governo sozinho não consegue ser responsável em criar valor para o público, pois é preciso uma atitude cívica para utilizar as tecnologias.

Os avanços tecnológicos podem exacerbar a desigualdade. Pelo menos inicialmente, os detentores de poder e voz estão em melhor posição para adquirir e adaptar novas tecnologias, fazendo com que as prioridades de atividades de pesquisa e desenvolvimento sejam canalizadas para satisfazer suas necessidades. [...] Somente $1 \%$ dos novos medicamentos comercializados entre 1975 e 1996 foi desenvolvido pra o tratamento de doenças tropicais. Dez anos depois, e a despeito de alguns esforços filantrópicos, essa disparidade permanece: somente 10\% do orçamento global para pesquisas na área da saúde (US\$ 50 a 60 bilhões) são gastos com doenças que afetam 90\% da população do mundo (GREEN, 2009, p. 60)

Destarte, podemos afirmar que uma tecnologia é cívica quando é promotora do engajamento, participação ou melhora do relacionamento entre os cidadãos e o governo, 
bem como entre os próprios cidadãos, o que auxilia na redução de ciclos viciosos de desinformação, desigualdade e pobreza.

O primeiro passo para reverter nossa situação é reconhecer que ser humano é um esporte de equipe. Não podemos ser totalmente humanos sozinhos. Qualquer coisa que nos reúna promove nossa humanidade. Da mesma forma, tudo o que nos separa nos torna menos humanos e menos capazes de exercer nossa vontade individual ou coletiva (RUSHKOFF, 2019, p. 8).

Reconhecido isso, é possível se comunicar em 6 vias:

4 vias Top-down (de cima para baixo)

- G2C-Government-to-citizen (do governo para os cidadãos);

- G2B-Government-to-business (do governo para as empresas);

- G2G-Government-to-government (do governo para governo);

- G2E-Government-to-employees (do governo para funcionários).

Nesse tipo de via de comunicação estão as iniciativas do governo para se comunicar com os seus públicos, com vistas à avaliação de serviços públicos, criação de plataformas de interação, disponibilização de dados e conteúdos, implementação e melhoria de processos e serviços existentes.

1 via horizontal:

- $\mathrm{C} 2 \mathrm{C}$ - Citizen-to-citizen (de cidadão para cidadão)

Elenca as tecnologias que melhoram os processos de comunicação entre os cidadãos, com vistas a um melhor uso dos recursos, organização para "cobrarem" o governo, bem como melhor exercer seus direitos e deveres.

1 via bottom-up (de baixo para cima):

- C2G - Citizen-to-government (de cidadão para o governo)

Esta via trata das tecnologias criadas fora do âmbito governamental; diz respeito às tecnologias que melhoram a frequência e qualidade da interação entre cidadãos e o governo. 
É válido ressaltar que, independentemente da via de comunicação das tecnologias cívicas, o primordial é que elas tenham como foco a capacitação dos cidadãos para gerar suas soluções, criar ferramentas e encontrar novas formas de auto-organização.

Nós podemos e devemos intervir nas máquinas e nas tecnologias. As tecnologias cívicas consistem na aceitação do progresso e, por consequência, das tecnologias, mas incorporando os valores humanos ao desenvolvimento delas. A adoção, disseminação e cocriação delas permite uma reconstituição ética do ser humano, combatendo o inimigo pelo seu centro, logo "temos o dever de relembrar e proclamar os valores que estão sendo deixados para trás." (RUSHKOFF, 2020, p. 154).

Na obra denominada Inteligência Coletiva: por uma antropologia do ciberespaço, o professor francês tenta construir, epistemologicamente, alguns referenciais sobre a influência da velocidade, das transformações da informática e das tecnologias.

O autor define inteligência coletiva como:

[...] uma inteligência distribuída por toda parte, constantemente valorizada, coordenada em tempo real, que leva a uma efetiva mobilização de competências. Acrescentamos a essa definição essa ideia indispensável: a base e o objetivo da inteligência coletiva é o reconhecimento mútuo e o enriquecimento das pessoas (LEVY, 2004, p. 20)

O grande projeto da inteligência coletiva é o de propiciar o estabelecimento de relações entre indivíduos que antes não podiam se relacionar, mas que hoje, devido ao ciberespaço, podem desenvolver vínculos; assim, “o ideal da inteligência coletiva implica a avaliação técnica, econômica, jurídica e humana de uma inteligência distribuída em todos os lugares, a fim de desencadear uma dinâmica positiva de reconhecimento e mobilização de competências." (LEVY, 2004, p. 21).

É importante compreender que as tecnologias não causam impacto, pois, concordando com Levy (2000), elas não surgem do espaço sideral e caem na Terra; nós, historicamente, construímos, desenvolvemos e disseminamos tais tecnologias, assim "não podemos separar o mundo material - e menos ainda sua parte artificial - das ideias por meio das quais os objetos são concebidos e utilizados, nem dos humanos que os inventam, produzem e utilizam." (LEVY, 2000, p. 22).

É o momento de reconciliar as inteligências de todos, criando um grande cérebro global, afinal, "se nossas sociedades se contentarem em ser inteligentemente dirigidas, 
com certeza falharão em seus objetivos. Para ter alguma chance de viver melhor, elas devem se tornar inteligentes na massa." (LEVY, 2004, p. 22).

O primeiro elemento motor do desenvolvimento é o descontentamento com o estado atual e a ânsia por um estado desejado, em que a educação assume uma função insubstituível, seja como precursora de ferramentas estratégicas de ação ou na formação de pessoas que desejam estados desenvolvidos (FERNANDES JÚNIOR et al. 2019, p. 141)

Se antes apenas recebíamos a notícia, hoje temos as ferramentas para criar a notícia. Se antes, éramos convidados a participar de manifestações populares, hoje podemos ser os organizadores destas. Atualmente, estamos, por quase $50 \%$ do tempo que passamos acordados, imersos no ciberespaço, seja no trabalho ou respondendo mensagens em aplicativos de redes sociais.

Por intermédio do celular, que é um computador, filmamos, tiramos fotos, gravamos, escrevemos, e compartilhamos nossas criações no ciberespaço. No ciberespaço, ao contrário do que acontecia com os meios tradicionais (televisão, por exemplo), não conseguimos controlar a mensagem que disseminamos; uma simples brincadeira postada pode ser compartilhada e nunca mais conseguir ser apagada.

Por intermédio da pesquisa de Backstrom et al. (2012), que mapeou os 721 milhões de usuários do Facebook e suas 69 bilhões de conexões de amizade, descobriu-se que estamos apenas a 4 degraus de separação da pessoa mais distante no mundo, isto é, os indivíduos estão cada vez mais próximos e, assim, podemos nos beneficiar desse progresso.

Nesse contexto, Douglas Rushkoff (2019) nos convida a reafirmar a agenda humana, utilizando as potencialidades das tecnologias; assim, com o espírito cívico do jogo em equipe, podemos retomar as rédeas.

\section{CONSIDERAÇÕES FINAIS}

Não serão os robôs, as blockchains e nem a Inteligência Artificial que resolverão os problemas que não foram criados por elas. O alcance de valores humanos mais elevados, como a justiça universal, por exemplo, não será resolvido por algoritmos de aprendizado de máquinas; apenas trabalhando conjuntamente conseguiremos chegar mais longe. 
Nossas tecnologias mais avançadas não estão melhorando nossa conectividade, mas a frustrando. As tecnologias estão substituindo e desvalorizando nossa humanidade e, de inúmeras maneiras, estão minando nosso respeito uns pelos outros e por nós mesmos. Infelizmente, isso foi intencional; contudo, também é por isso que esse processo pode ser revertido (RUSHKOF, 2019). Essa solidão conectada consiste na escolha das relações por meio da tecnologia digital (TURKLE, 2011); destarte, é, também, uma solidão psicológica individualista, um isolamento sistemático e reprodutivo de grupos que não têm e não terão acesso às inovações, mas apenas ao controle e indução ao e pelo consumo.

Algumas expectativas com relação à disponibilização e o advento da internet não foram atendidas. Por fim, aceitamos o fato de sermos controlados pelas tecnologias; ao invés de controlá-las, ao invés de nos conectarmos, nos desconectamos fisicamente.

Ainda há um grande caminho a ser percorrido para termos internet em todos os lugares, redução de ciclos de pobreza, discriminação e injustiça, melhores canais de comunicação entre população e governo, entre outros. Devemos buscar chegar cada vez mais próximo do grande projeto da inteligência coletiva - de promover as relações humanas que eram tolhidas pela ausência das tecnologias.

Destarte, as tecnologias devem ser usadas para geração de melhores canais de comunicação entre poder público e privado visado o bem público e comum, bem como o desenvolvimento de formas de auto-organização. O acidente integral preconizado por Paul Virilio é iminente, mas, se trabalharmos em conjunto, ele pode ser mitigado.

\section{REFERÊNCIAS}

ABBAGNANO, Nicola. Dicionário de Filosofia. São Paulo: Martins Fontes, 2007.

BACKSTROM, L. et al. Four Degrees of Separation. 2012. Disponível em: http://www.leonidzhukov.net/hse/2015/sna/papers/websci12-fourdegrees.pdf. Acesso em: 10 abr. 2018.

BAUMAN, Zygmunt; BORDONI, Carlo. Estado de Crise. Rio de Janeiro: Zahar, 2016.

CASTELLS, Manuel. The rise of the network society. 2. ed. Oxford: Wiley-Blackwell, 2010. (Information age).v.1.

DE MASI, D. O futuro chegou: modelos de vida para uma sociedade desorientada. Rio de Janeiro: Casa da Palavra, 2014. 
DIGITAL 2021 APRIL GLOBAL STATSHOT REPORT. DataReport, [S.I.], 2021. Disponível em: https://datareportal.com/reports/digital-2021-april-global-statshot. Acesso em: 25 abr. 2021.

DIGITAL 2021 INDIA. DataReport, [S.I.], 2021. Disponível em: https://datareportal.com/reports/digital-2021-india?rq=india. Acesso em: 2 maio 2021.

DIGITAL 2021 BANGLADESH. DataReport, [S.I.], 2021. Disponível em: https://datareportal.com/reports/digital-2021-bangladesh?rq=bangladesh. Acesso em: 2 maio 2021.

FERNANDES JÚNIOR, Alvaro Martins. ALMEIDA, Siderly do Carmo Dahle de Almeida. OLIVEIRA, Marivaldo da Silva Oliveira. BRUZAMOLIN, Amanda Louise. Virtude e sabedoria: uma reflexão ética para a sociedade do conhecimento. Colloquium Humanarum, Presidente Prudente, v. 16, n. 2, p.134-145, abr./jun. 2019.

FERNANDES JÚNIOR, Alvaro Martins. ALMEIDA, Siderly do Carmo Dahle de Almeida. ESTEVES, Silvio Renato Moretto. Gestão do conhecimento, educação e desenvolvimento: a propiciação do Bá da evolução. In: OLIVEIRA, Ricardo Daher et al. Pensando o conhecimento: uma abordagem teórica à gestão do conhecimento. Maringá: Humanitas Vivens, 2015.

GREEN, D. Da pobreza ao poder: Como cidadãos ativos e estados efetivos podem mudar o mundo. São Paulo: Cortez; Oxford: Oxfam International, 2009.

GRIJPINK, F.; MÉNARD, A.; SIGURDSSON, H.; VUCEVIC, N. The road to 5g: The inevitable growth of infrastructure cost. McKinsey\& Company, [S.I.], 2018. Disponível em: https://www.mckinsey.com/industries/technology-media-and-telecommunications/ourinsights/the-road-to-5g-the-inevitable-growth-of-infrastructure-cost?cid=other-eml-altmip-mck-oth1802\&hlkid=4108a3016b4842dfac49of90465f61f4\&hctky=9411404\&hdpid=1156041 . Acesso em: 05 ago. 2021.

ITU Publications. Measuring the Information Society Report: Volume 1. 2018. Disponível em: https://www.itu.int/en/ITU-D/Statistics/Documents/publications/misr2018/MISR-2018Vol-1-E.pdf. Acesso em: 05 ago. 2021.

LEVY, Pierre. Cibercultura. São Paulo: Editora 34, 2000.

LEVY, Pierre. A inteligência colectiva: por una antropologia del ciberespacio. Washington: OMS, 2004.

LYOTARD, J.F. O pós-moderno. 3. ed. Rio de Janeiro: José Olympio, 1986.

MARTINO, Luis Mauro Sá. Teoria das Mídias Digitais: Linguagens, ambientes e redes. Petrópolis: Vozes, 2014. 
MEDEIROS, Pedro. Uma introdução à teoria da democracia. Curitiba: InterSaberes, 2016.

NOHARA, Irene Patrícia; COLOMBO, Bruna Armonas. Tecnologias cívicas na interface entre direito e inteligência artificial: Operação Serenata de Amor para gostosuras ou travessuras? A\&C - Revista de Direito Administrativo \& Constitucional, Belo Horizonte, ano 19, n. 76, p. 83-103, abr./jun. 2019. DOI: 10.21056/aec.v19i76.1100.

SARTORI, Giovanni. A teoria da Democracia revisitada: o debate contemporâneo. São Paulo: Ática, 1994. v.1

SEVCENKO, Nicolau. A corrida para o século XXI: No loop da montanha-russa. São Paulo: Companhia das Letras, 2001. (Virando séculos; 7).

SKARŽAUSKIENĖ, A.; MAČIULIENĖ, M. Mapping International Civic Technologies

Platforms. Informatics, [S.I.], v. 7, n. 46, 2020. DOI:

https://doi.org/10.3390/informatics7040046.

RUSHKOFF, Douglas. Team Human. New York: W. W. Norton \& Company, 2019.

RUSHKOFF, Douglas. Program or be programmed: Ten commands for a digital age. New York: OR Books, 2010.

TURKLE, Sherry. Alone Together: Why We Expect More from Technology and Less from Each Other. New York: Basic Books, 2011.

WEINER, Eric. Onde nascem os gênios. São Paulo: Dark Side books, 2016.

ZlžEK, Slavoj. Problema no Paraíso: Do fim da história ao fim do capitalismo. Rio de Janeiro: Zahar, 2015. 